\title{
Low-temperature heat emission combined with seasonal thermal storage and heat pump
}

\author{
Arefeh Hesaraki*, Armin Halilovic, Sture Holmberg \\ Division of Fluid and Climate Technology, School of Architecture and the Built Environment, KTH Royal Institute of Technology, Stockholm, Sweden
}

Received 1 March 2015; received in revised form 26 May 2015; accepted 15 June 2015

Communicated by: Associate Editor Ruzhu Wang

\begin{abstract}
We studied the application of a stratified seasonal hot water storage tank with a heat pump connected to medium-, low- and very-low-temperature space heat emissions for a single-family house in Stockholm, Sweden. Our aim was to investigate the influence of heat emission design temperature on the efficiency and design parameters of seasonal storage in terms of collector area, the ratio of storage volume to collector area (RVA), and the ratio of height to diameter of storage tank. For this purpose, we developed a mathematical model in MATLAB to predict hourly heat demand in the building, heat loss from the storage tank, solar collector heat production, and heat support by heat pump as a backup system when needed. In total, 108 cases were simulated with RVAs that ranged from 2 to $5\left(\mathrm{~m}^{3} \mathrm{~m}^{-2}\right)$, collector areas of 30,40 , and $50\left(\mathrm{~m}^{2}\right)$, height-to-diameter-of-storage-tank ratios of $1.0,1.5$, and $2.0\left(\mathrm{~m} \mathrm{~m} \mathrm{~m}^{-1}\right)$, and various heat emissions with design supply/return temperatures of 35/30 as very-low-, 45/35 as low-, and 55/45 ( $\left.{ }^{\circ} \mathrm{C}\right)$ as medium-temperature heat emission. In order to find the best combination based on heat emission, we considered the efficiency of the system in terms of the heat pump work considering coefficient of performance (COP) of the heat pump and solar fraction. Our results showed that, for all types of heat emission a storage-volume-to-collector area ratio of $5 \mathrm{~m}^{3} \mathrm{~m}^{-2}$, with a collector area of $50 \mathrm{~m}^{2}$, and a height-to-diameter ratio of $1.0 \mathrm{~m} \mathrm{~m}^{-1}$ were needed in order to provide the maximum efficiency. Results indicated that for very-low-temperature heat emission the heat pump work was less than half of that of the medium-temperature heat emission. This was due to $7 \%$ higher solar fraction and $14 \%$ higher COP of heat pump connected to very-low-temperature heat emission compared to medium-temperature heat emission.
\end{abstract}

(C) 2015 Elsevier Ltd. All rights reserved.

Keywords: Seasonal thermal energy storage; Stratified storage tank; Heat pump; Low-temperature heat emission

\section{Introduction}

The building sector uses about $40 \%$ of total primary energy and contributes to $35 \%$ of global greenhouse gas emissions (European Commission, 2011). The EU's roadmap for long-term low carbon development is to decrease carbon emissions by $80 \%$ by 2050 compared to the 1990

\footnotetext{
* Corresponding author at: Brinellvägen 23, 10044 Stockholm, Sweden. Tel.: +46879048 84 .

E-mail address: arefeh.hesaraki@byv.kth.se (A. Hesaraki).
}

level in order to keep temperature change below $2{ }^{\circ} \mathrm{C}$ (European Commission, 2011). This shows the importance of improving heating systems in the residential sector, which accounted for almost $15 \%$ of total European greenhouse gas emissions in 2011 (European Commission, 2011). Using renewable energy such as solar energy, and biomass or low-carbon heat sources, such as district heating, heat pumps or heat storage instead of fossil fuels would greatly reduce $\mathrm{CO}_{2}$ emissions and the environmental loads of fossil fuels. In Swedish district heating system, the heat source of more than $60 \%$ of heat production was from renewable 


\section{Nomenclature}

$\overline{\mathbf{h}} \quad$ average convective heat transfer coefficient $\begin{array}{ll}\dot{m}_{\text {coll }} & \text { between layers }\left(\mathrm{W} \mathrm{m}^{-2} \mathrm{~K}^{-1}\right) \\ \text { mass flow rate to collector array }\left(\mathrm{kg} \mathrm{s}^{-1}\right)\end{array}$

$\dot{m}_{\mathrm{H}} \quad$ mass flow rate to the heating system $\left(\mathrm{kg} \mathrm{s}^{-1}\right)$

a experimentally determined linear loss coefficient of collector $\left(\mathrm{W} \mathrm{m}^{-2} \mathrm{~K}^{-1}\right)$

A collector area $\left(\mathrm{m}^{2}\right)$

$A_{\text {base,layer }}$ base area of layer $\left(\mathrm{m}^{2}\right)$

$A_{n} \quad$ surface area of layer $\left(\mathrm{m}^{2}\right)$

$b \quad$ experimentally determined quadratic loss coefficient of collector $\left(\mathrm{W} \mathrm{m}^{-2} \mathrm{~K}^{-2}\right.$ )

COP coefficient of performance of heat pump (-)

$c_{p} \quad$ specific heat capacity of water $\left(\mathrm{J} \mathrm{kg}^{-1} \mathrm{~K}^{-1}\right)$

$g \quad$ gravity $\left(\mathrm{m} \mathrm{s}^{-2}\right)$

Gr Grashof number (-)

HDR height-to-diameter ratio of storage tank $\left(\mathrm{m} \mathrm{m}^{-1}\right)$

HP heat pump

$k_{f} \quad$ thermal conductivity of fluid $\left(\mathrm{W} \mathrm{m}^{-1} \mathrm{~K}^{-1}\right)$

$L_{\mathrm{c}} \quad$ characteristic length, defined as a ratio of the layer's base area to its perimeter (m)

LTH low-temperature heat emission

$m_{\text {layer }} \quad$ mass of water in each layer $(\mathrm{kg})$

MTH medium-temperature heat emission

$n \quad$ layer number from 1 to 10

$\eta_{0} \quad$ collector efficiency (\%)

$\eta_{\mathrm{c}} \quad$ Carnot efficiency of heat pump (\%)

$\mathrm{Nu} \quad$ Nusselt value (-)

$P_{\text {in }} \quad$ input power for each layer (W)

$P_{\text {natural }} \quad$ free convection $(\mathrm{W})$

$P_{\text {out }} \quad$ output power from each layer (W)

$\operatorname{Pr}$
Prandtl number (-)
$Q_{\mathrm{hd}} \quad$ heat demand in the building ( $\left.\mathrm{kW} \mathrm{h}\right)$

$Q_{\text {loss }} \quad$ heat loss from storage tank $(\mathrm{kW} \mathrm{h})$

$Q_{\text {storage }} \quad$ storage capacity $(\mathrm{kW} \mathrm{h})$

$Q_{\text {c }} \quad$ heat production by solar collector $(\mathrm{kW} \mathrm{h})$

$Q_{\mathrm{HP}} \quad$ heat provided by heat pump (kW h)

$q_{\mathrm{r}} \quad$ solar radiation $\left(\mathrm{W} \mathrm{m}^{-2}\right)$

$R a \quad$ Rayleigh number (-)

Re Reynolds number (-)

RVA ratio of storage volume to collector area $\left(\mathrm{m}^{3} \mathrm{~m}^{-2}\right)$

SF $\quad$ solar fraction $(\%)$

$U_{\text {tank }}$ heat transfer coefficient of storage tank ( $\mathrm{W} \mathrm{m}^{-2} \mathrm{~K}^{-1}$ )

VLTH very-low-temperature heat emission

$W_{\mathrm{HP}} \quad$ electricity consumption by heat pump $(\mathrm{kW} \mathrm{h})$

$\beta \quad$ thermal expansion coefficient $\left(\mathrm{K}^{-1}\right)$

$\Delta t \quad$ time span between two calculations (h)

$\theta_{\text {amb }} \quad$ ambient temperature $\left({ }^{\circ} \mathrm{C}\right)$

$\theta_{\text {coll }} \quad$ collector temperature $\left({ }^{\circ} \mathrm{C}\right)$

$\theta_{\mathbf{H}} \quad$ water supply temperature to heat emission $\left({ }^{\circ} \mathrm{C}\right)$

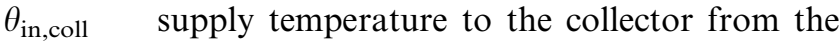
lowest layer of seasonal storage $\left({ }^{\circ} \mathrm{C}\right)$

$\theta_{\text {in,HP }} \quad$ supply temperature to the heat pump from the top layer of seasonal storage $\left({ }^{\circ} \mathrm{C}\right)$

$\theta_{\mathrm{n}} \quad$ layer temperature $\left({ }^{\circ} \mathrm{C}\right)$

$\theta_{\text {out,coll }}$ outgoing temperature from collector to the top layer of seasonal storage $\left({ }^{\circ} \mathrm{C}\right)$

$\theta_{\text {out,HP }}$ outgoing temperature from heat pump to the lowest layer of seasonal storage $\left({ }^{\circ} \mathrm{C}\right)$

$\theta_{\text {soil }} \quad$ ground temperature $\left({ }^{\circ} \mathrm{C}\right)$

$v \quad$ kinematic viscosity $\left(\mathrm{m}^{2} \mathrm{~s}^{-1}\right)$ sources and only 13\% came from oil products by 2012 (Swedish District Heating Association, 2012). In high-latitude countries, however, the scarcity of solar radiation during winter highlights the application of seasonal thermal energy storage (Lund, 1984). In seasonal thermal energy storage, heat is stored during summer and is used during winter (Hasnain, 1998). This heat can be stored in rock, soil, aquifers or water tanks (Novo et al., 2010; Xu et al., 2014; Pavlov and Olesen, 2012). Sweden became the first country to implement a seasonal storage, following the oil crisis of the 1980s (Ochs et al., 2009). Since then, several seasonal heating systems have been built and designed in Europe and other countries, (Schmidt et al., 2004; Paksoy et al., 2004; Wang et al., 2010; Fischa et al., 1998; Sibbitt et al., 2012; Milewski et al., 2014)

Due to heat losses, unpredictable living habits and weather condition, an auxiliary heat source is essential to cover the peak load and total heating demand during the whole heating season. A heat pump (HP) is recommended as an efficient supplementary system to be combined with seasonal storage (Lund, 1984; Hesaraki and Holmberg, 2015). Due to the use of renewable energies stored in air, ground or water, heat pumps typically use three to four times less electrical energy than direct electrical heaters to deliver the same amount of heat. There are different ways to combine heat pump with seasonal thermal energy storage and solar thermal collector, including parallel, serial, and parallel-serial configurations (Sparber et al., 2011). In parallel configuration, heat pump and solar collector (seasonal storage) work independently to meet the heat demand in building. In serial combination, however, solar collector (seasonal storage) acts as a source for heat pump, exclusively or in addition to other sources. With regards to serial-parallel method, heat pump or collector provides heat to the building, dependently or independently. Combining heat pump with seasonal storage in serial, or serial-parallel configuration is beneficial because it reduces the return temperature to the storage tank. This reduction 
helps keep the storage tank stratified (Gari and Loehrke, 1982) which causes higher collector efficiency and lower heat loss to the surrounding ground (Duffie and Beckman, 2006). Furthermore, a higher coefficient of performance (COP) of the heat pump is a result of a stratified tank because the temperature supplied to the evaporator of the heat pump from the top layer of the stratified tank is higher than that of a mixed tank.

Yumrutas and Unsal (2012) developed an analytical and computational model to investigate the influence that the earth type, year of operation, Carnot efficiency of the heat pump and collector and storage sizes have on the COP of heat pumps and storage temperature in hot water tank seasonal storage. Their results showed that using a larger collector area and greater storage volume increased the COP of heat pumps, especially after the fifth year of operation. Vanhoudt et al. (2011) monitored the operation of aquifer thermal energy storage with a heat pump for heating and cooling a hospital in Belgium over a period of three years. Their results showed a $71 \%$ reduction in primary energy usage compared to conventional gas-fired boilers. Durao et al. (2014) used a Genetic Algorithm in the MATLAB simulation tool to find the optimum size for a seasonal hot water storage tank and collector area for heating a greenhouse. Their aim was to reach $100 \%$ solar fraction without any backup system. Chung et al. (1998) used the TRNSYS simulation tool to model seasonal storage in three different cities in South Korea. They studied the influence of storage volume and collector area on solar fraction. Their results showed that the solar fraction has an approximately linear relation to collector area and logarithmic relation with storage volume. They suggested avoiding oversized storage tanks or undersized collector areas due to the high solar energy loss during heating season. Milewski et al. (2014) developed an analytical model to investigate the influence of the size of the seasonal storage tank and collector area on the efficiency of the system in Polish climates. Their results showed that a solar fraction of $70 \%$ needs a half dimension in the storage tank and $30 \%$ smaller collector area compared to the size of the system providing $100 \%$ solar fraction. This size reduction would result in significant cost savings. However, it should be noted that for renewable sources most of the cost is due to the initial cost which has been decreased during recent years, and the operating cost is the minor part of the total cost. This is in contrast to the cost for fossil fuel-based heating system in which the investment cost is negligible and the total cost mainly depends on the price of fuels which has almost tripled since 1996 in Sweden (Energy in Sweden, 2013).

All of the abovementioned studies have investigated the performance of seasonal storage with different storage and collector sizes, earth types and collector types. However, the influence of heat emission temperature on efficiency and the design parameters of seasonal storage remains undetermined. On the demand side in buildings, there could be different heat emissions with different design temperatures, which would influence efficiency and the size of the storage. The main objective of this paper was to study the impact of different space heat emissions on performance and the design parameters of seasonal storage in terms of the ratio of storage volume to collector area (RVA), and the height-to-diameter ratio (HDR) of the storage tank and the required collector area. For this purpose three types of heat emissions with different supply/return temperature were considered: that is, those with medium temperature $\left(55 / 45^{\circ} \mathrm{C}\right)$, low temperature $\left(45 / 35^{\circ} \mathrm{C}\right)$ and very low temperature $\left(35 / 30{ }^{\circ} \mathrm{C}\right)$. In order to find the most efficient seasonal storage considering the heat pump work, two parameters that indicated the efficiency of the system as the COP of the heat pump and the solar fraction $(\mathrm{SF})$ were considered.

\subsection{Description of the building}

A recently-built single-family house located in Stockholm, Sweden was considered as a case study. The seasonal solar heating storage for this building as shown in Fig. 1 was assumed as follows:

1. The solar collector on the roof is used to charge the tank buried under the ground. The heat production from solar collector can be used directly if the produced temperature is high enough. Otherwise, it is used to charge the water tank.

2. The hot water tank is buried deep under the ground, so the thermal loss is reduced due to not depending on outside temperature variation. In this case, the storage is exposed to a constant ground temperature over the year. This storage is used directly for heating demand as long as the temperature is sufficient for direct usage.

3. The heat pump is served by the hot water tank as a heat source when the temperature of storage is not enough to be used directly.

4. The house has a medium-, low-, or very-low-temperature heating system.

The total roof area for the selected building was $55 \mathrm{~m}^{2}$, which meant that collector areas of 30,40 and $50\left(\mathrm{~m}^{2}\right)$ were considered. In addition, with a stratified tank the height of the tank is preferred to be higher than its diameter (Shtrakov and Stoilov, 2006). Therefore, the values of $1.0,1.5$, and 2.0 were used as the height-to-diameter ratio (HDR). From practical point of views, the values more than 2.0 are not favored. Also, since the volume of the storage tank has an effect on the seasonal storage tank temperature different RVAs were considered. Refereeing to previous studies (Novo et al., 2010; Hesaraki and Holmberg, 2015) the values ranging from 2 to $5 \mathrm{~m}^{3} \mathrm{~m}^{-2}$ were considered for RVA in most projects. Therefore, the same ranges were used in this study. In total, 108 cases were considered in order to find the best solution considering collector area (A), RVA and HDR of storage tank based on the heat emission for this building (see Table 1). 


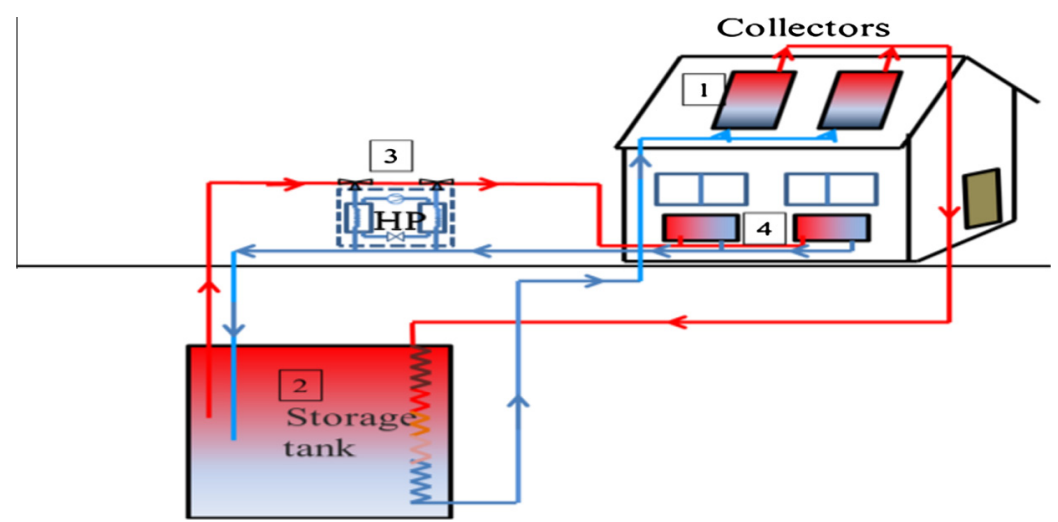

Fig. 1. Seasonal thermal energy storage system, including solar collector, storage tank, heat pump and medium-, low- or very-low-temperature heating system.

Table 1

Different case studies with various heat emissions, collector areas (A), HDR, and RVA.

\begin{tabular}{|c|c|c|c|c|}
\hline Heat emission & HDR & Case number & $A\left(\mathrm{~m}^{2}\right)$ & $\operatorname{RVA}\left(\mathrm{m}^{3} \mathrm{~m}^{-2}\right)$ \\
\hline $\begin{array}{l}\text { Medium temperature heat emission }(\mathrm{MTH}) \\
\text { Design supply/return temperature } 55 / 45^{\circ} \mathrm{C}\end{array}$ & $\begin{array}{l}1.0 \\
1.5 \\
2.0\end{array}$ & $\begin{array}{l}1-12 \\
13-24 \\
25-36\end{array}$ & $\begin{array}{l}30,40,50 \\
30,40,50 \\
30,40,50\end{array}$ & $\begin{array}{l}2,3,4,5 \\
2,3,4,5 \\
2,3,4,5\end{array}$ \\
\hline $\begin{array}{l}\text { Low-temperature heat emission (LTH) } \\
\text { Design supply/return temperature } 45 / 35^{\circ} \mathrm{C}\end{array}$ & $\begin{array}{l}1.0 \\
1.5 \\
2.0\end{array}$ & $\begin{array}{l}37-48 \\
49-60 \\
61-72\end{array}$ & $\begin{array}{l}30,40,50 \\
30,40,50 \\
30,40,50\end{array}$ & $\begin{array}{l}2,3,4,5 \\
2,3,4,5 \\
2,3,4,5\end{array}$ \\
\hline $\begin{array}{l}\text { Very-low-temperature heat emission (VLTH) } \\
\text { Design supply/return temperature } 35 / 30{ }^{\circ} \mathrm{C}\end{array}$ & $\begin{array}{l}1.0 \\
1.5 \\
2.0\end{array}$ & $\begin{array}{l}73-84 \\
85-96 \\
97-108\end{array}$ & $\begin{array}{l}30,40,50 \\
30,40,50 \\
30,40,50\end{array}$ & $\begin{array}{l}2,3,4,5 \\
2,3,4,5 \\
2,3,4,5\end{array}$ \\
\hline
\end{tabular}

\section{Method}

An analytical approach was the main method used in this study. A dynamic model was developed in MATLAB to study the behavior of the system under different conditions. The required input data were climatic file (that is, radiation and mean ambient temperature), building properties (such as, location, building materials and ventilation rates), storage insulation material, ground temperature, collector area, RVA, and HDR of the storage tank. Based on these variables, the behavior of the system was studied hourly.

The climatic file was provided for every hour by Swedish Meteorological and Hydrological Institute. Therefore, the starting point for all calculations was the heat balance for every hour between demand, loss and supply to maintain indoor temperature around $21^{\circ} \mathrm{C}$; see Eq. (1).

$Q_{\text {storage }}=Q_{\mathrm{c}}+Q_{\mathrm{HP}}-Q_{\mathrm{hd}}-Q_{\text {loss }}$

As Eq. (1) shows, heat stored in the storage tank $\left(Q_{\text {storage }}\right)$ is equal to all heat input to the system, including heat produced by the solar collector $\left(Q_{\mathrm{c}}\right)$ and heat provided by the heat pump $\left(Q_{\mathrm{HP}}\right)$, minus all heat output from the system including heat demand in building $\left(Q_{\mathrm{hd}}\right)$, and heat loss to the surrounding ground ( $\left.Q_{\text {loss }}\right)$.
To calculate heat demand in the building $\left(Q_{\mathrm{hd}}\right)$, space heat loss and ventilation heat loss were considered. The heat production from solar collector $\left(Q_{\mathrm{c}}\right)$, as described in Eq. (2), depends on the availability of solar radiation, the outdoor temperature and the collector temperature, which depends on the seasonal storage tank temperature, which varies along the hour. During low or no solar radiation at nights or in dark winter days, $Q_{\mathrm{c}}$ becomes zero or negative. In this case there is no circulation in solar collector and consequently the storage tank is not charged.

$Q_{\mathrm{c}}=A \cdot \Delta t \cdot\left[\eta_{0} \cdot q_{\mathrm{r}}-a \cdot\left(\theta_{\text {coll }}-\theta_{\mathrm{amb}}\right)-b \cdot\left(\theta_{\text {coll }}-\theta_{\mathrm{amb}}\right)^{2}\right]$

where $\Delta t$ is one hour, $\eta_{0}$ is the collector efficiency, $A$ is the collector area $\left(\mathrm{m}^{2}\right), q_{\mathrm{r}}$ is the solar radiation $\left(\mathrm{W} \mathrm{m}^{-2}\right), a$ and $b$ are the experimentally determined linear $\left(\mathrm{W} \mathrm{m}^{-2} \mathrm{~K}^{-1}\right)$ and quadratic $\left(\mathrm{W} \mathrm{m}^{-2} \mathrm{~K}^{-2}\right)$ loss coefficients of the collector, respectively. $\theta_{\text {coll }}$ and $\theta_{\text {amb }}$ are the collector temperature, which is the average of the inlet and outlet temperatures of the collector, and the ambient temperature $\left({ }^{\circ} \mathrm{C}\right)$, respectively.

The colder water was at the bottom of the storage tank, which fed the solar collector. The upper part of the tank was used to cover the heat demand. Depending on the heat 
output of the collector and the heat demand by the building, the heat produced by the solar collector is used for immediate usage and/or for charging the tank for later usage. It means that if the temperature produced by the solar collector is enough for direct usage it goes directly to the radiators, and heat pump is not in operation. However, when the temperature produced by the solar collector is insufficient to be used directly, solar collector or thermal storage tank act as a source for heat pump and the temperature is upgraded by the heat pump to the suitable level for the heating system. In other word, if the stored heat in the storage was less than the heat demand, this extra demand was covered by heat pump support $\left(Q_{\mathrm{HP}}\right)$; see Eq. (3) Yumrutas and Unsal, 2012.

$Q_{\mathrm{HP}}=W_{\mathrm{HP}} \cdot C O P$

where $W_{\mathrm{HP}}$ is electricity needed by heat pump, $C O P$ is coefficient of performance of heat pump, $Q_{\mathrm{HP}}$ is the heat covered by heat pump which is equal to the difference between the total heat demand and the heat demand covered by solar energy $(\mathrm{kW} \mathrm{h})$,

Regarding heat pump efficiency, the $C O P$ of the heat pump is considered based on the electricity used by the heat pump to increase the temperature of the water in the top layer of the storage tank $\left(\theta_{\mathrm{in}, \mathrm{HP}}\right)$ to the level required by the heat emission $\left(\theta_{\mathrm{H}}\right)$, as shown by Eq. (4).

$C O P=\eta_{\mathrm{c}}\left(\frac{\theta_{\mathrm{H}}(t)}{\theta_{\mathrm{H}}(t)-\theta_{\mathrm{in}, \mathrm{HP}}(\mathrm{t})}\right)$

where $\eta_{\mathrm{c}}$ is the Carnot efficiency of heat pump (the relation between the efficiency under real conditions and the theoretically maximum reachable efficiency), $\theta_{\mathrm{H}}$ and $\theta_{\mathrm{in}, \mathrm{HP}}$ is the temperature of the supply water to the heat emission and the supply temperature to the heat pump from the top layer of seasonal storage, respectively $\left({ }^{\circ} \mathrm{C}\right)$.

Heat loss from each layer of the storage tank ( $\left.Q_{\text {loss }}\right)$ depends on the temperature difference between the ground $\left(\theta_{\text {soil }}\right)$ and the layer temperature $\left(\theta_{\mathrm{n}}\right)$, the surface area of the layer $\left(A_{\mathrm{n}}\right)$ and the heat transfer coefficient of the storage tank $\left(U_{\text {tank }}\right)$; see Eq. (5).

$Q_{\text {loss }}=\Delta t \cdot \sum_{n=1}^{10} U_{\mathrm{tank}} \cdot A_{n} \cdot\left(\theta_{n}-\theta_{\mathrm{soil}}\right)$

where $n$ is the number of layer from 1 to $10, U_{\text {tank }}$ is the heat transfer coefficient of the storage tank $\left(\mathrm{W} \mathrm{m}^{-2} \mathrm{~K}^{-1}\right)$, $A_{n}$ is the surface area of layer $\left(\mathrm{m}^{2}\right)$, and $\theta_{\mathrm{n}}$ and $\theta_{\text {soil }}$ are the temperatures of the layer and the ground $\left({ }^{\circ} \mathrm{C}\right)$, respectively.

In order to decrease the heat loss, it was assumed that the cylindrical seasonal storage tank was well insulated and was buried deep underground. The ground temperature was considered to be held equal to the mean annual outdoor temperature throughout the year. The required inlet temperature to the heating system was calculated based on the heat emission installed in building. Three heat emission types were considered: conventional radiator (design supply/return temperature of $55 / 45^{\circ} \mathrm{C}$ ), forced convection radiator (design supply/return temperature of $45 / 35^{\circ} \mathrm{C}$ ) and floor heating (design supply/return temperature of $35 / 30^{\circ} \mathrm{C}$ ).

In addition, the solar fraction showing the amount of energy provided by the solar heating system divided by the total energy demand (shown by Eq. (6)) is an important factor to consider when evaluating the efficiency of the system.

$S F=\frac{Q_{\mathrm{c}}-Q_{\mathrm{loss}}}{Q_{\mathrm{hd}}}$

Considering two parameters of $S F$ and $C O P$, work done by heat pump can be calculated by Eq. (7).

$W_{H P}=\frac{(1-S F)}{C O P} \cdot Q_{h d}$

Stratified storage tank was divided into 10 layers with the same thickness (Durao et al., 2014). As long as the tank is charged by the solar collector and discharged by the house or the heat pump throughout the whole year, the tank is most likely to stay stratified. In addition, the shape of the tank with HDR of one or more helps to keep the tank stratified. Eight years temperature monitoring of the stratified seasonal hot water storage tank in Friedrichshafen, Germany, showed the temperature difference of 5 and $20^{\circ} \mathrm{C}$ between the top and bottom layer throughout the whole years (Schmidt and Nusbicker, 2005).

Energy balance equations were calculated for each single layer for every hour, as in Eq. (8).

$m_{\text {layer }} \cdot c_{\mathrm{p}} \cdot \frac{\Delta \theta_{\mathrm{n}}}{\Delta t}=\sum P_{\text {in }}-\sum P_{\text {out }}$

where $m_{\text {layer }}$ is the mass of water in each layer $(\mathrm{kg}), c_{\mathrm{p}}$ is the specific heat capacity of the water $\left(\mathrm{J} \mathrm{kg}^{-1} \mathrm{~K}^{-1}\right), \theta_{\mathrm{n}}$ is the layer temperature $\left({ }^{\circ} \mathrm{C}\right)$, and $P_{\text {in }}$ and $P_{\text {out }}$ are the input and output power for each layer (W).

Considering the boundary condition around the storage tank, the input heat was solar heat to the top layer $\left(\dot{m}_{\text {coll }} \cdot c_{\mathrm{p}} \cdot \theta_{\text {out,coll }}\right)$, and the condenser heat from the heat pump (building) to the lowest layer $\left(\dot{m}_{\mathrm{H}} \cdot c_{\mathrm{p}} \cdot \theta_{\text {out }, \mathrm{HP}}\right)$. The heat output from the tank was the heat from the top layer to the heat pump (building) $\left(\dot{m}_{\mathrm{H}} \cdot c_{\mathrm{p}} \cdot \theta_{\mathrm{in}, \mathrm{HP}}\right)$, and to the collector from the lowest layer $\left(\dot{m}_{\text {coll }} \cdot c_{\mathrm{p}} \cdot \theta_{\text {in,coll }}\right)$ and also the heat loss to the surrounding ground through all layers; see Fig. 2. As can be seen in Fig. 2, in addition to the external thermal exchange, there were internal thermal interactions between different layers inside the tank. This was due to the temperature difference and the free convection $\left(P_{\text {natural }}\right)$ between layers. To find out if there is any forced or mixed convection between layers, the relative magnitudes of Grashof (which shows the ratio of buoyancy and viscosity within a fluid) and the Reynolds number (that is, the ratio of momentum to viscous forces) was used. This Gr-to-Re ratio is a generally accepted indication for 


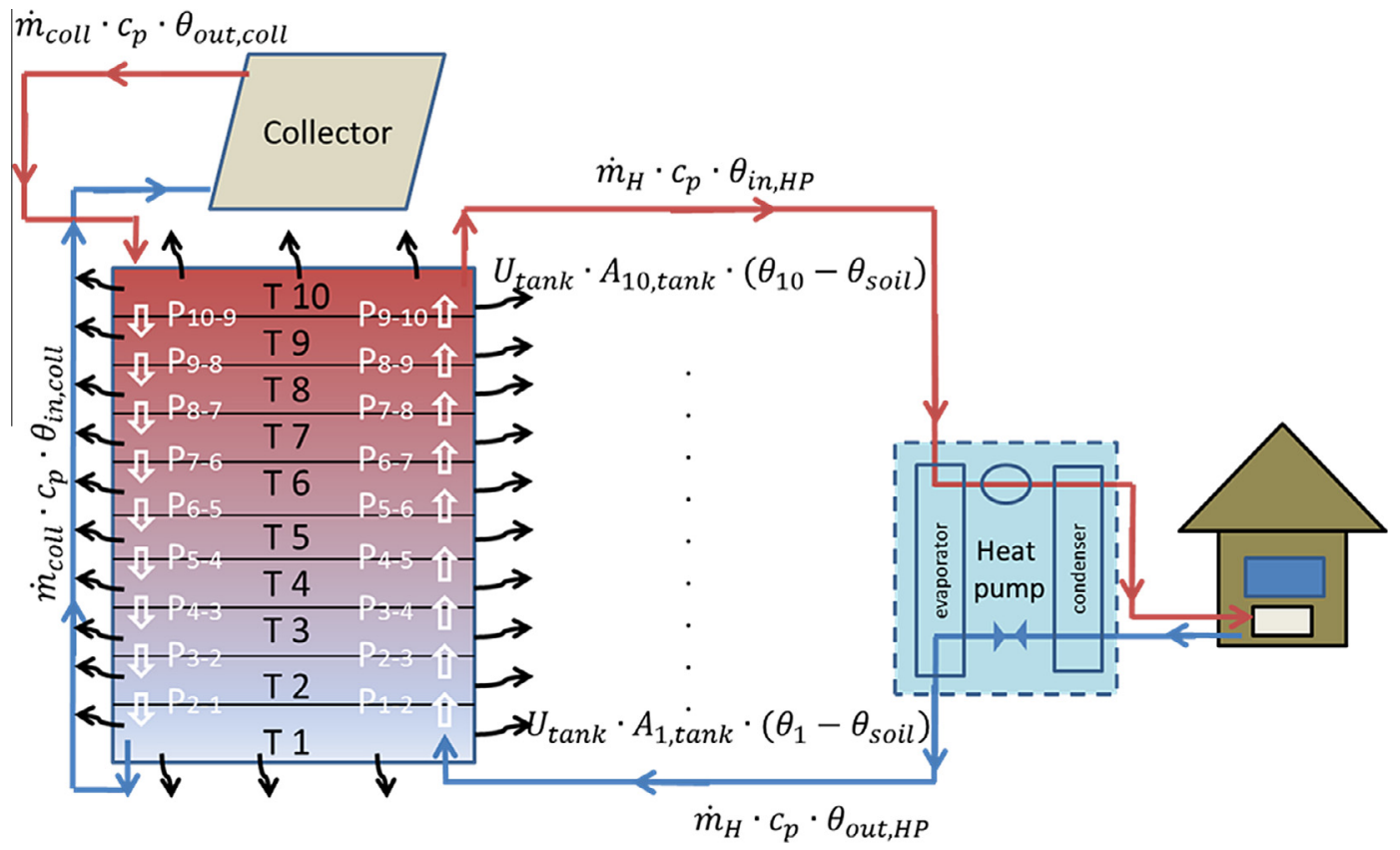

Fig. 2. Heat balance for different layers of storage tank.

determining the type of heat transfer including natural, forced and mixed convection. If $G r / R e^{2} \geqslant 10$ forced convection is usually insignificant and when $G r / R e^{2} \ll 1$, natural convection effects may be neglected. When this ratio is between one and ten, mixed convection must be taken into account. In our case, $G r / R e^{2}$ was much higher than 10 , which indicates that free convection only existed between layers. Heat exchanges between layers $(n=1,2$, ..., 9) were determined using Eqs. 9-13 Durao et al., 2014.

$P_{\text {natural }_{n \rightarrow n+1}}=\bar{h}_{n \rightarrow n+1} \cdot A_{\text {base, layer }} \cdot\left(\theta_{n}-\theta_{n+1}\right)$

$P_{\text {natural }_{n+1 \rightarrow n}}=\bar{h}_{n \rightarrow n+1} \cdot A_{\text {base, layer }} \cdot\left(\theta_{n+1}-\theta_{n}\right)$

$\bar{h}_{n \rightarrow n+1}=\frac{N u_{n \rightarrow n+1} \cdot k_{\mathrm{f}}}{L_{\mathrm{c}}}$

where $\overline{\mathrm{h}}$ is the average convective heat transfer coefficient $\left(\mathrm{W} \mathrm{m}{ }^{-2} \mathrm{~K}^{-1}\right), A_{\text {base,layer }}$ is the base area of layer $\left(\mathrm{m}^{2}\right)$ equal to $\pi$ (radius) $)^{2}, N u$ is the Nusselt value as a dimensionless number showing the ratio of convective to conductive heat transfer, $k_{\mathrm{f}}$ is the thermal conductivity of fluid $\left(\mathrm{W} \mathrm{m}^{-1} \mathrm{~K}^{-1}\right.$ ), and $L_{\mathrm{c}}$ is the characteristic length defined as a ratio of layer base area to its perimeter $(\mathrm{m})$.

The average Nusselt number for the lower surface of the hot plate or the upper surface of the cold plate for $10^{5}<\mathrm{Ra}<10^{11}$ is defined as in Eq. (12) Bergman et al., 2007.

$N u_{n \rightarrow n+1}=0.27 R a_{L_{n \rightarrow n+1}}^{1 / 4}$

where the Rayleigh $(R a)$ value is a dimensionless number defined as the product of the dimensionless Grashof number $(G r)$, and the Prandtl number (Pr); see Eq. (13). $P r$ shows the relationship between momentum diffusivity and thermal diffusivity.
$R a_{L_{n \rightarrow n+1}}=G r_{L_{n \rightarrow n+1}} \cdot \operatorname{Pr}=\frac{g \cdot \beta \cdot L_{c}^{3} \cdot\left(\frac{\theta_{n}+\theta_{n+1}}{2}-\theta_{n}\right)}{v^{2}} \cdot \operatorname{Pr}$

where $g$ is gravity $\left(\mathrm{m} \mathrm{s}^{-2}\right), \beta$ is thermal expansion coefficient $\left(\mathrm{K}^{-1}\right)$, and $v$ is kinematic viscosity $\left(\mathrm{m}^{2} \mathrm{~s}^{-1}\right)$.

The parameters used in MATLAB are shown in Table 2. For the solar collector, a single glazed flat plate collector with selective absorber was used. With regard to heat demand, a recently-built single-family house from the previous study was chosen (Hesaraki and Holmberg, 2013). In order to investigate only the impact of the heat emission temperature on the efficiency of seasonal storage, domestic hot water consumption was not considered.

\section{Results and discussion}

All 108 cases with different system sizes and heat emissions were simulated in MATLAB. The starting date for simulation was 1st May 2013, with an initial uniform storage temperature of $10{ }^{\circ} \mathrm{C}$. Simulation was run for a whole year till 30th April 2014. The COP of the heat pump and the solar fraction (SF) as two important efficiency indicators for designing the system were taken into account. Figs. 3-5 show the COP and SF for various RVAs and the HDR of the storage tank for medium-temperature, low-temperature and very-low-temperature heat emissions, respectively. As these figures show, keeping the collector area constant and increasing the RVA cause a higher COP. This was due to more stable and higher temperature in the top layer when increasing the storage volume; in other words, the heat pump needs to do less work. However, as can be seen in all cases this correspondence between RVA and COP gradually tapered off until the ratio of storage volume to collector area become sufficient 
to store all heat produced by collector and the temperature in the top layer of storage tank becomes approximately constant over the year. Furthermore, increasing RVA would result in higher SF; however, with little enhancement. This could be due to more storage heat capacity as well as more collector efficiency due to more stable temperature and there being no sudden jump in inlet temperature to the collector. In addition, increasing HDR would cause lower solar fraction. The reason is higher heat loss from the storage tank with higher HDR due to more surface area with the same volume expose to surrounding. Also, increasing collector area causes higher SF and COP due to more captured solar energy by collector and greater temperature in storage tank which favors both collector and heat pump efficiency. Depending on collector area, RVA and HDR, the heat pump COP connected to medium-temperature heat emission ranged between 2.3 and 3.7. These values for low-temperature heat emission were between 2.6-4.0. In case of very-low-temperature heat emission these ranges are the highest, i.e. between 2.8 and 4.3. Solar fraction varies between $72-85 \%, 76-89 \%$, and $79-92 \%$ for medium-, low-, and very-low-temperature heat emission, respectively. As can be seen in all cases, both SF and COP for very-low-temperature heat emission were higher than those of the other systems.

The optimization objective was used to find the optimum values for RVA and HDR for each type of heat emission with collector area of 30,40 and $50 \mathrm{~m}^{2}$. The objective was to minimize the work done by the HP, as shown earlier by Eq. (7). Least Square Method was used to find the minimum heat pump work for each type of heat emission and collector area as a function of two variables of RVA and HDR. For this purpose the second-degree polynomial as Eq. (13) was used to determine the parameters of a, b, c, $\mathrm{d}$, e, and $\mathrm{f}$.

$a x_{k}^{2}+b x_{k} y_{k}+c y_{k}^{2}+d x_{k}+e y_{k}+f=z_{k}$

where $z_{k}$ is $W_{\mathrm{HP}}, x_{k}$ is RVA, $y_{k}$ is HDR and subscript of $k$ is from 1 to 12 as the number of cases for each type of heat emission with collector area of 30,40 and $50 \mathrm{~m}^{2}$.

Figs. 6-8 show heat pump work graphs as a function of RVA and HDR for medium-, low- and very-low- temperature heat emission, respectively. As Figs. 6-8 show, for all types of heat emission the RVA of $5 \mathrm{~m}^{3} \mathrm{~m}^{-2}$, the collector area of $50 \mathrm{~m}^{2}$ and the HDR of 1.0 are needed for minimizing the work by heat pump. This was due to higher heat contribution by larger collector and lower heat loss by lower HDR.

Table 3 shows these optimum points with design parameters that provide the minimum heat pump work following highest efficiency regarding $\mathrm{COP}$ and SF. As the temperature of the heat emission decreases, the SF and the COP of the heat pump increase. For a very-low-temperature heating system, the COP of heat pump and SF were almost $14 \%$ and $7 \%$ higher compared to the medium-temperature heat emission. In addition to higher efficiency, this would

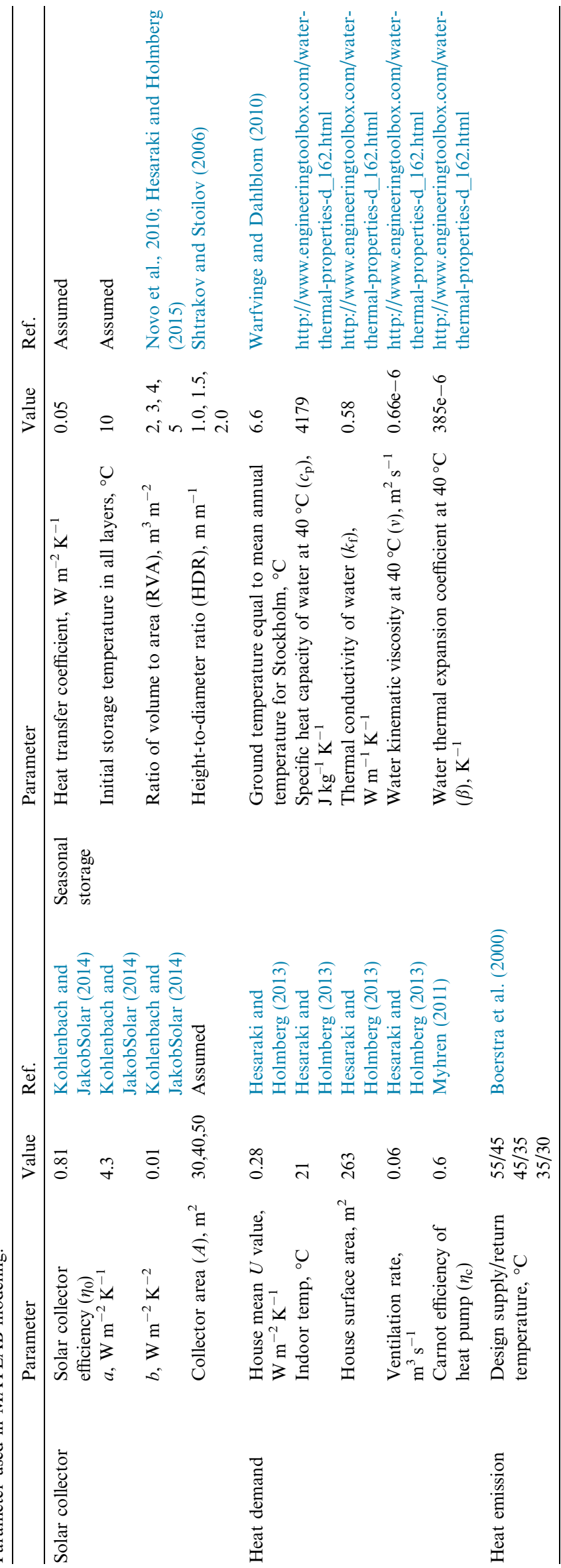



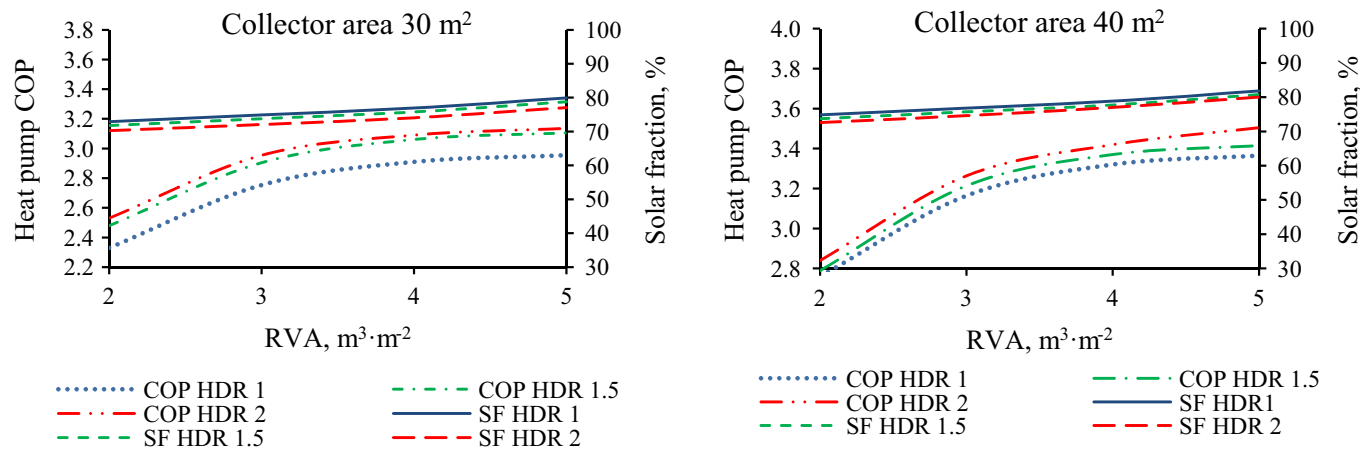

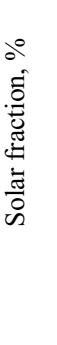
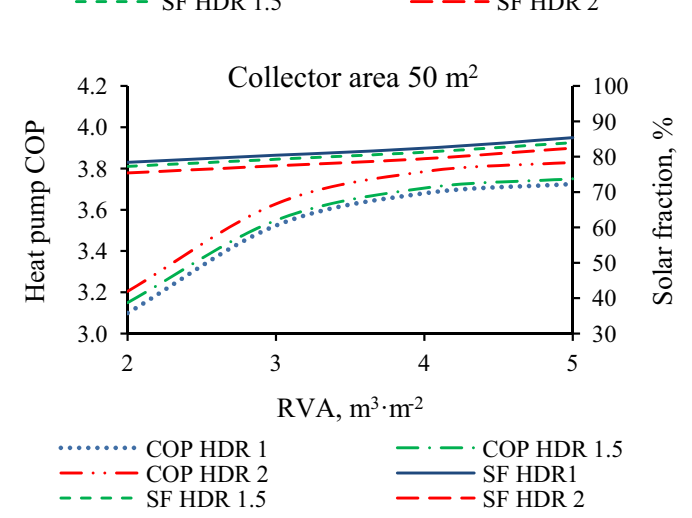

Fig. 3. Solar fraction and COP of the heat pump for a seasonal heating system connected to a medium-temperature heat emission with collector areas of $30 \mathrm{~m}^{2}$ (upper, left), $40 \mathrm{~m}^{2}$ (upper, right) and $50 \mathrm{~m}^{2}$ (lower) and HDRs of 1.0, 1.5 and 2.0 .
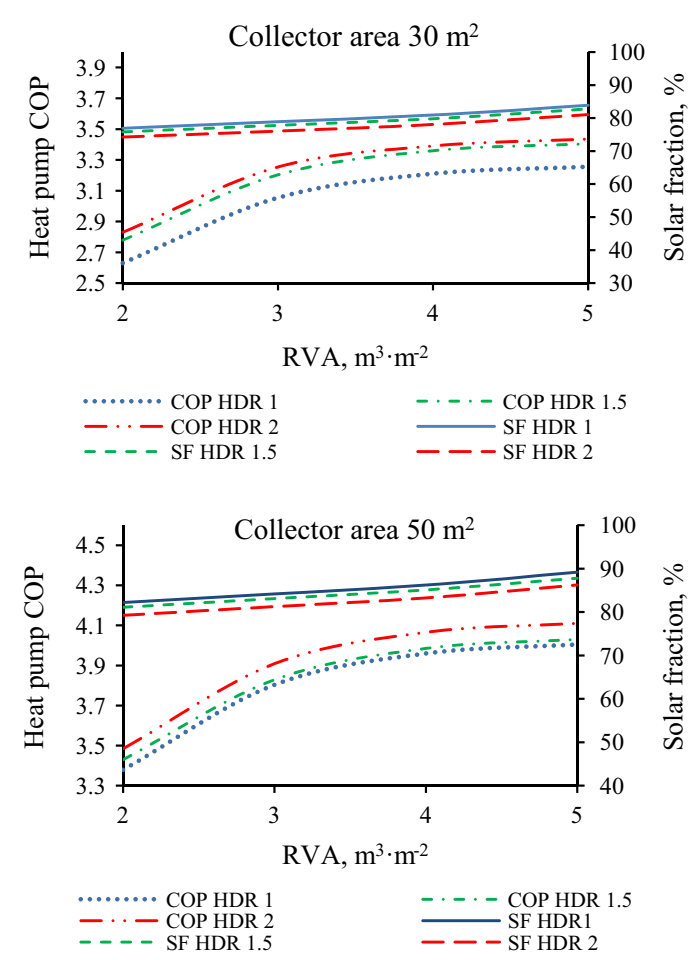

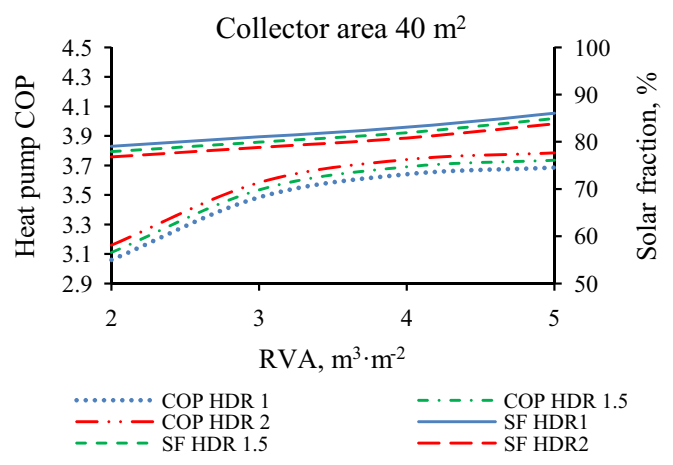

Fig. 4. Solar fraction and COP of a heat pump for a seasonal heating system connected to a low-temperature heat emission with collector areas of $30 \mathrm{~m}^{2}$ (upper, left), $40 \mathrm{~m}^{2}$ (upper, right) and $50 \mathrm{~m}^{2}$ (lower) and HDRs of 1.0, 1.5, and 2.0.

also cause less than half of heat pump work than that of the medium-temperature heat emission. Our results indicated that the highest COP and the highest SF were $4.25 \%$ and
$92 \%$ achieved by very-low-temperature heat emission connected to $50 \mathrm{~m}^{2}$ collector area and the storage tank with RVA of $5 \mathrm{~m}^{3} \mathrm{~m}^{-2}$, and HDR of 1 . 

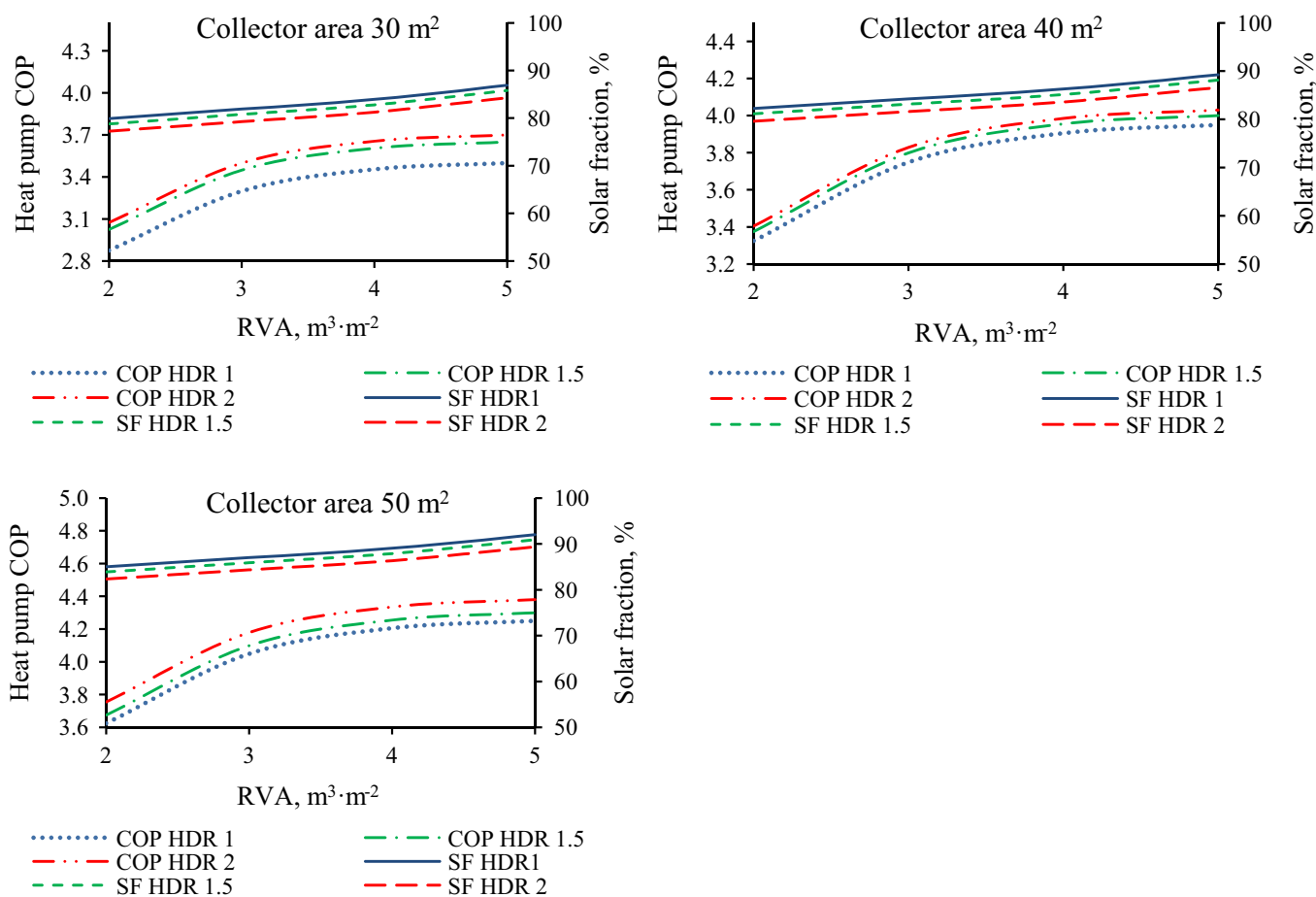

Fig. 5. Solar fraction and COP of a heat pump for a seasonal heating system connected to a very-low-temperature heat emission with collector areas of $30 \mathrm{~m}^{2}$ (upper, left), $40 \mathrm{~m}^{2}$ (upper, right) and $50 \mathrm{~m}^{2}$ (lower) and HDRs of 1.0, 1.5, and 2.0.

WHP (medium temp, collector area 30)

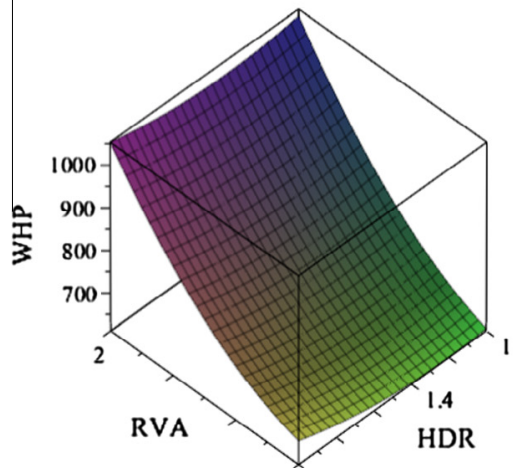

WHP (medium temp, collector area 40)

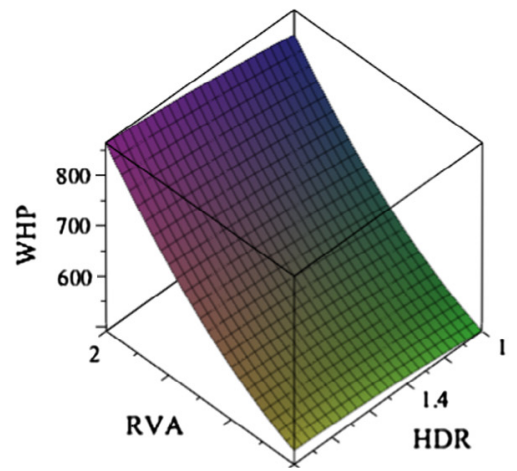

WHP (medium temp, collector area 50)

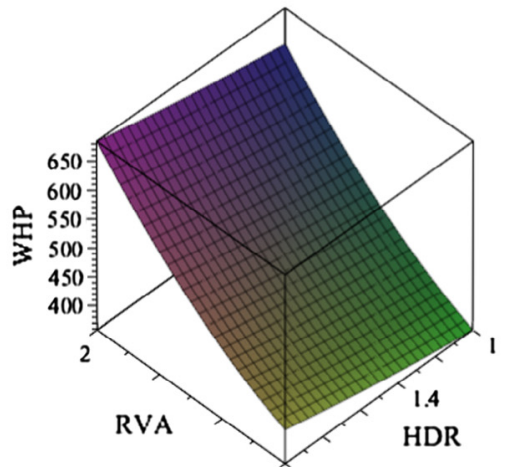

Fig. 6. Optimization objective for a medium-temperature heat emission with collector area of 30 (left), 40 (middle) and 50 (right) $\mathrm{m}^{2}$.
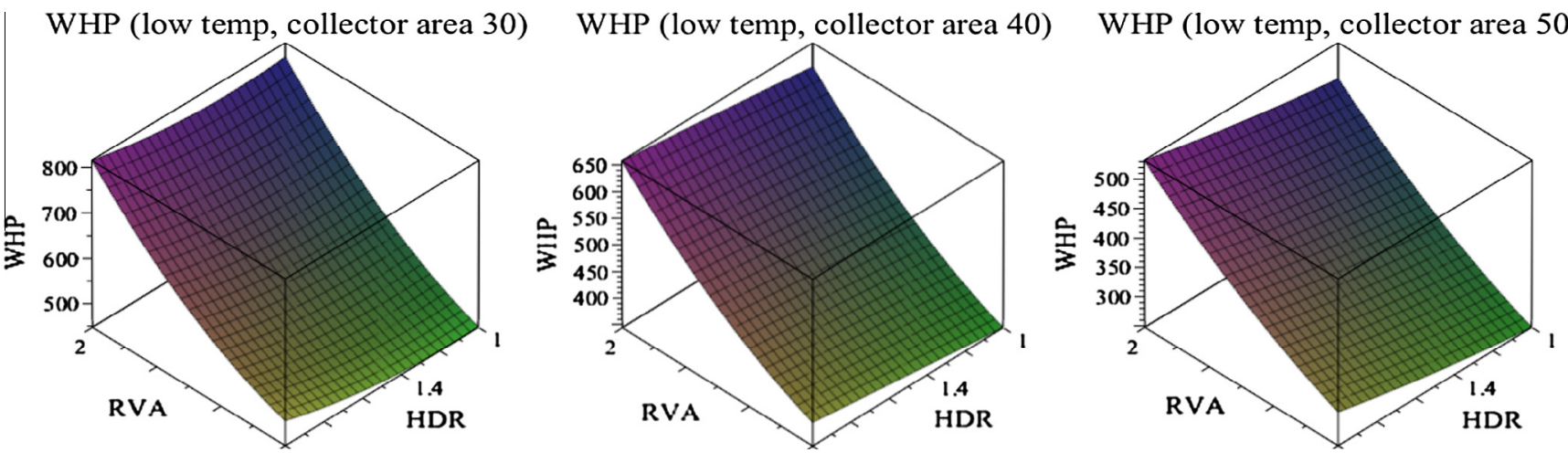

Fig. 7. Optimization objective for a low-temperature heat emission with collector area of 30 (left), 40 (middle) and 50 (right) $\mathrm{m}^{2}$. 
WHP (very low temp, collector area 30)

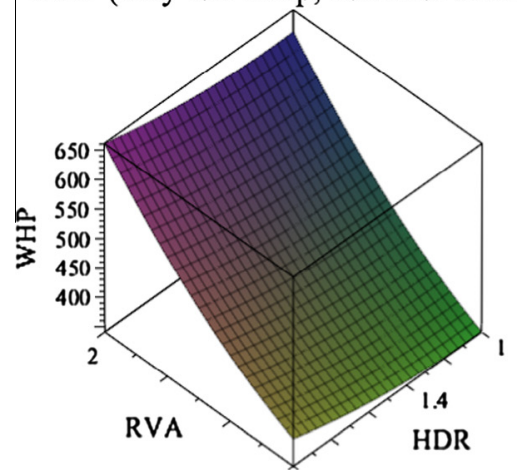

WHP (very low temp, collector area 40)

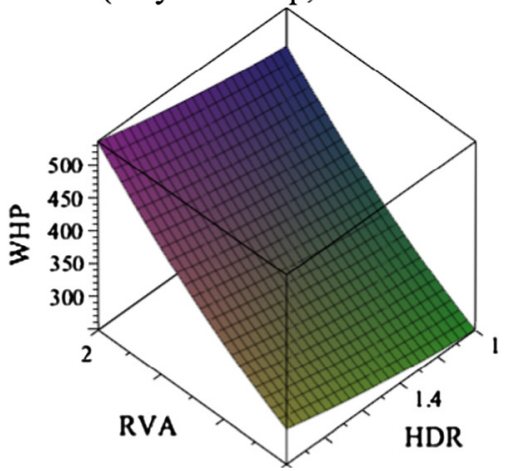

WHP (very low temp, collector area 50)

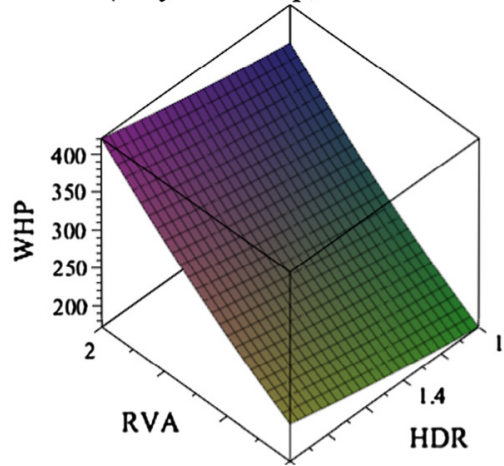

Fig. 8. Optimization objective for a very-low-temperature heat emission with collector area of 30 (left), 40 (middle) and 50 (right) $\mathrm{m}^{2}$.

Table 3

Seasonal storage system size connected to different heat emissions providing the highest efficiency.

\begin{tabular}{|c|c|c|c|c|c|c|c|}
\hline Heat emission & Storage volume (h, D) & HDR & $A,\left(\mathrm{~m}^{2}\right)$ & $\operatorname{RVA}\left(\mathrm{m}^{3} \mathrm{~m}^{-2}\right)$ & $\mathrm{SF}(\%)$ & $\mathrm{COP}$ & $W_{\mathrm{HP}}(\mathrm{kW} \mathrm{h})$ \\
\hline MTH emitter $\left(55 / 45^{\circ} \mathrm{C}\right)$ & $250(6.8,6.8)$ & 1.0 & 50 & 5 & 85.4 & 3.73 & 352.9 \\
\hline LTH emitter $\left(45 / 35^{\circ} \mathrm{C}\right)$ & $250(6.8,6.8)$ & 1.0 & 50 & 5 & 89.2 & 4.00 & 242.7 \\
\hline VLTH emitter $\left(35 / 30^{\circ} \mathrm{C}\right)$ & $250(6.8,6.8)$ & 1.0 & 50 & 5 & 92.0 & 4.25 & 169.5 \\
\hline
\end{tabular}

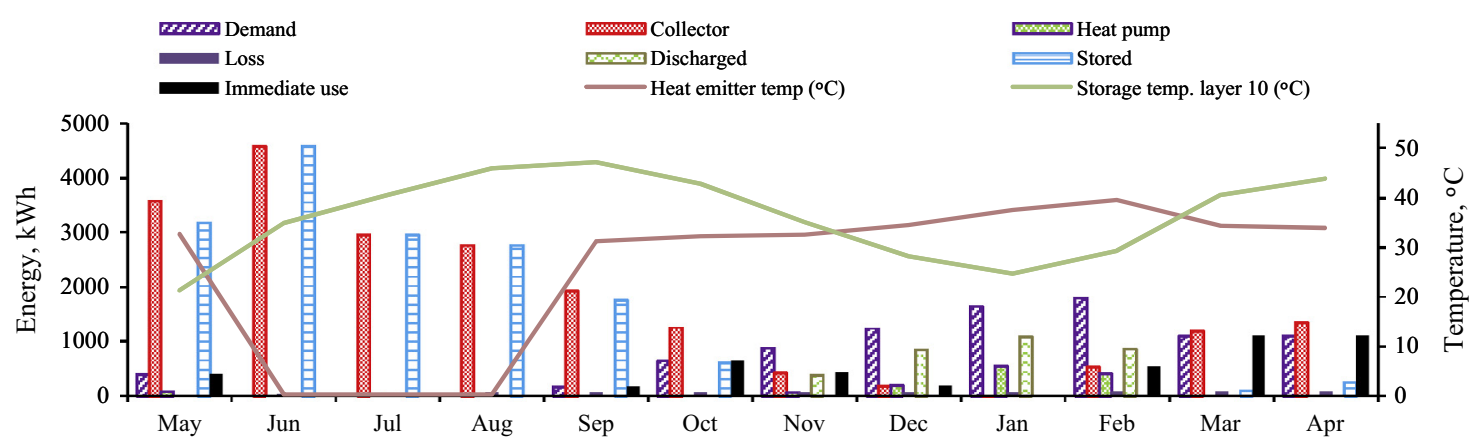

Fig. 9. Monthly energy balance and temperature for medium-temperature heat emission connected to a seasonal heating system with optimum design features of $50 \mathrm{~m}^{2}$ collector area and $5 \mathrm{~m}^{3} \mathrm{~m}^{-2} \mathrm{RVA}$ and HDR of 1.0.

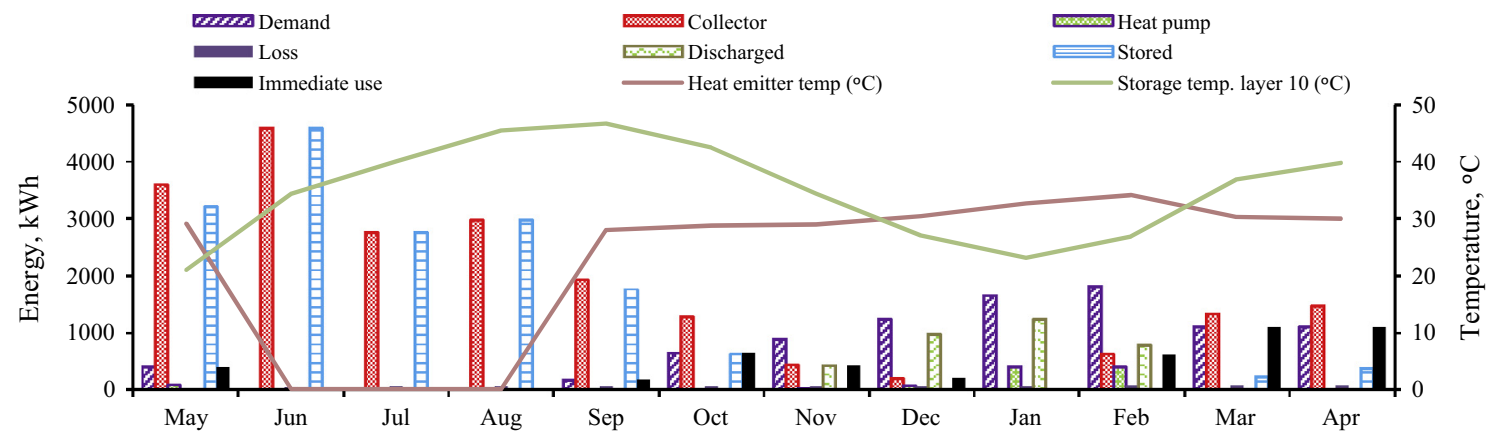

Fig. 10. Monthly energy balance and temperature for low-temperature heat emission connected to a seasonal heating system with optimum design features of $50 \mathrm{~m}^{2}$ collector area and $5 \mathrm{~m}^{3} \mathrm{~m}^{-2} \mathrm{RVA}$ and HDR of 1.0 .

Figs. 9-11 show the monthly energy balance, including the monthly heat demand, heat production by solar collector, heat stored in the storage, heat discharged, immediate use of heat and heat loss, as well as the temperature of the top layer of storage tank and heat emission for the optimum arrangement shown in Table 3 . As can be seen in 


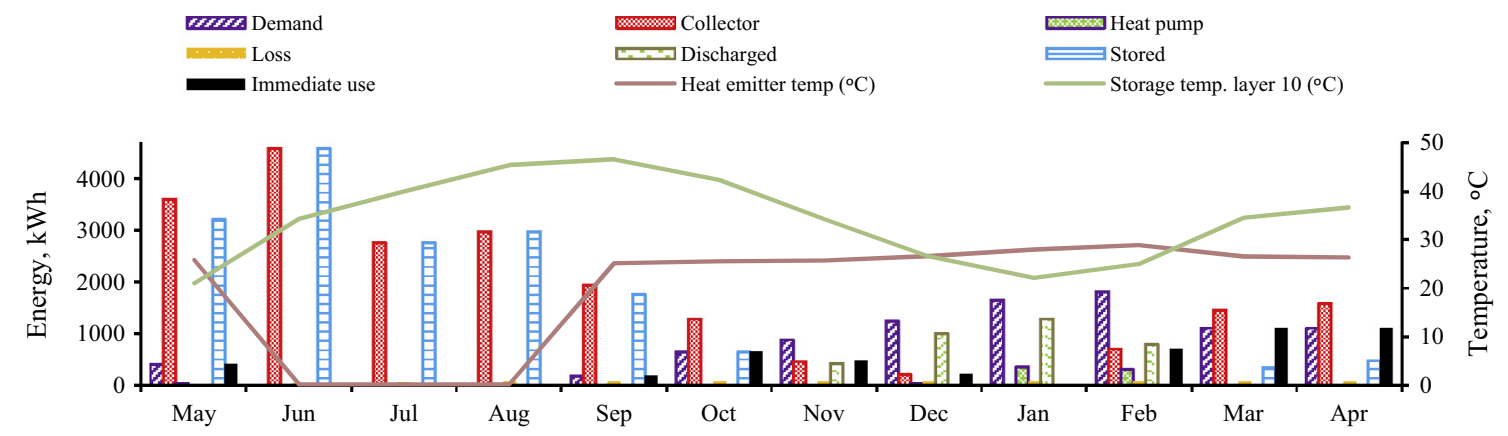

Fig. 11. Monthly energy balance and temperature for very-low-temperature heat emission connected to a seasonal heating system with optimum design features of $50 \mathrm{~m}^{2}$ collector area and $5 \mathrm{~m}^{3} \mathrm{~m}^{-2} \mathrm{RVA}$ and HDR of 1.0 .

Figs. 9-11, due to not considering domestic hot water all heat production by the collector during summer months was used for charging the storage tank. In October, collected solar energy was used both to cover heat demand and charging the storage tank. From November till February, all collector production was immediately used without charging the storage tank. Heat demand for December, January and February was mainly covered by discharged heat from storage. For all cases, the temperature of the top layer of storage tank was at its lowest level in January, requiring higher heat pump support than in other months.

\section{Conclusion}

The purpose of this study was to investigate the influence of heat emission types with design supply temperatures of 55,45 and $35\left({ }^{\circ} \mathrm{C}\right)$ on efficiency and design parameters of a stratified seasonal heat storage system. Three types of heat emissions were considered: a medium-temperature radiator, a low-temperature radiator and a very-low-temperature heating system. Different design parameters included the RVA, the HDR of the storage tank and the required collector area. Considering the RVA, four values ranging from 2 to $5\left(\mathrm{~m}^{3} \mathrm{~m}^{-2}\right)$ were used. Due to the requirement of the stratified storage tank having higher height than diameter, three values $(1,1.5$ and 2.0 $\left(\mathrm{m} \mathrm{m}^{-1}\right)$ ) were assumed to be the ratio of height to diameter. In addition, areas of 30,40 and $50\left(\mathrm{~m}^{2}\right)$ were used for the collector array. In total, with the various combinations of the different heat emissions, 108 cases were simulated in MATLAB. The results showed that, for all types of heat emission the larger RVA $\left(5 \mathrm{~m}^{3} \mathrm{~m}^{-2}\right)$ with the largest collector area $\left(50 \mathrm{~m}^{2}\right)$ and lower HDR $\left(1.0 \mathrm{~m} \mathrm{~m}^{-1}\right)$ are required for providing the maximum efficiency of system in terms of minimizing the heat pump work. For very-low-temperature heat emission, the SF and COP of heat pump were $7 \%$ and $14 \%$ higher than that in medium-temperature heat emission. This resulted in less than half required work by heat pump when connected to very-low-temperature heat emission. This shows the importance of moving toward a lower temperature heat emission in order to increase the efficiency of the system. It should be noted that this study was of one dwelling only in Sweden. However, our results in terms of having more sustainability and efficiency in heating system with lower supply temperature connected to seasonal storage could be generalized to other applications.

\section{Acknowledgements}

We are grateful to the Swedish Energy Agency (Energimyndigheten) and SBUF, The Development Fund of the Swedish Construction Industry for financial support. We also wish to thank Adnan Ploskic for feedback and Nima Khalilzad for helping with MATLAB modeling.

\section{References}

Bergman, T.L., Lavine, A.S., Incropera, F.P., DeWitt, D.P., 2007. Fundamentals of Heat and Mass Transfer. John Wiley \& Sons, Inc..

Boerstra, A., Veld, P.O., Eijdems, H., 2000. The health, safety and comfort advantages of low temperature heating systems: a literature review. In: Proceedings of the 6th International Conference on Healthy Buildings.

Chung, M., Park, J.U., Yoon, H.K., 1998. Simulation of a central solar heating system with seasonal storage in Korea. Sol. Energy 64, 163 178.

Communication from the Commission to the European Parliament, the Council, the European Economic and Social committee and the Committee of the Regions: A Roadmap for moving to a competitive low-carbon economy in 2050. European Commission, Brussels, 2011

Duffie, J.A., Beckman, W.A., 2006. In: Madison (Ed.), Solar engineering of thermal processes, third ed., John Wiley \& Son, US

Durao, B., Joyce, A., Mendes, J.F., 2014. Optimization of a seasonal storage solar system using genetic algorithms. Sol. Energy 101, 160 166.

Energy in Sweden 2013, Swedish Energy Agency, 2014.

Fischa, M.N., Guigas, M., Dalenbäck, J.O., 1998. A review of large-scale solar heating systems in Europe. Sol. Energy 63, 355-366.

Gari, H.N., Loehrke, R.I., 1982. A controlled buoyant jet for enhancing stratification in a liquid storage tank. J. Fluids Eng. 104, 475-481.

Hasnain, S.M., 1998. Review on sustainable thermal energy storage technologies, part i: heat storage materials and techniques. Energy Convers. Manage. 39, 1127-1138.

Hesaraki, A., Holmberg, S., 2013. Energy performance of low-temperature heating systems in five new-built Swedish dwellings: a case study using simulations and on-site measurements. Build. Environ. 64, 8593. 
Hesaraki, A., Holmberg, S., Haghighat, F., 2015. Seasonal thermal energy storage with heat pumps and low temperatures in building projects - a comparative review. Renew. Sustain. Energy Rev. 43, 1199-1213.

engineeringtoolbox.com/water-thermal-properties-d_162.html.

Kohlenbach, P., JakobSolar, U., 2014. Cooling: The Earthscan Expert Guide to Solar Cooling Systems, first ed. Routledge, New York, NY.

Lund, P.D., 1984. A comparative study of community solar heating systems for northern high latitudes. Int. J. Sol. Energy 2, 233-247.

Lund, P.D., 1984. Optimization of a community solar heating system with a heat pump and seasonal storage. Sol. Energy 33, 353-361.

Milewski, J., Wolowicz, M., Bujalski, W., 2014. Methodology for choosing the optimum architecture of a STES system. J. Power Technol. 94, 153-164.

Milewski, J., Wołowicz, M., Bujalski, W., 2014. Seasonal thermal energy storage - a size selection. Appl. Mech. Mater. 467, 270-276.

Myhren, J.A., 2011. Potential of ventilation radiators: performance evaluation by numerical, analytical and experimental investigations. Stockholm, Sweden: Doctoral Thesis in Civil and Architectural Engineering; KTH Royal Institute of Technology.

Novo, A.V., Bayon, R.J., Castro-Fresno, D., Rodriguez-Hernandez, J., 2010. Review of seasonal heat storage in large basins: water tanks and gravel-water pits. Appl. Energy 87, 390-397.

Ochs, F., Heidemann, W., Müller-Steinhagen, H., 2009. Performance of large-scale seasonal thermal energy stores. J. Sol. Energy Eng. 131 (4).

Paksoy, H.O., Gurbuz, Z., Turgut, B., Dikici, D., Evliya, H., 2004. Aquifer thermal storage (ATES) for airconditioning of a supermarket in Turkey. Renew. Energy 29, 1991-1996.

Pavlov, G.K., Olesen, B.W., 2012. Thermal energy storage - a review of concepts and systems for heating and cooling applications in buildings: Part 1 - Seasonal storage in the ground. HVAC\&R Res. 18, 515-538.

Schmidt, T., Nusbicker, J., 2005. Monitoring results from German central solar heating Plant with seasonal storage. In: Proceedings of ISES 2005 Solar World Congress, Orlando, Florida USA, August 2005.
Schmidt, T., Mangold, D., Muller-Steinhagen, H., 2004. Central solar heating plants with seasonal storage in Germany. Sol. Energy 76, 165 174 .

Shtrakov, S., Stoilov, A., 2006. Mathematical modelling of the thermal accumulation in hot water solar systems. Cornell University Library 2006. arXiv:cs/0607083.

Sibbitt, B., McClenahan, D., Djebbar, R., Thorntonb, J., Wong, B., Carriere, J., Kokko, J., 2012. The performance of a high solar fraction seasonal storage district heating system - five years of operation. Energy Proc. 30, 856-865.

Sparber, W., Vajen, K., Herkel, S., Ruschenberg, J., Thür, A., Fedrizzi, R.D́., Antoni, M., 2011. Overview on solar thermal plus heat pump systems and review of monitoring results IEA Task 44/Annex 38 publication/outcome. Int. Energy Agency.

Swedish District Heating Association. Statistics for supplied energy to district heating production, 2012, <http://www.svenskfjarrvarme.se $>$.

Vanhoudt, D., Desmedt, J., Van Bael, J., Robeyn, N., Hoes, H., 2011. An aquifer thermal storage system in a Belgian hospital: long-term experimental evaluation of energy and cost savings. Energy Build. $43,3657-3665$.

Wang, X., Zheng, M., Zhang, W., Zhang, S., Yang, T., 2010. Experimental study of a solar-assisted ground-coupled heat pump system with solar seasonal thermal storage in severe cold areas. Energy Build. 42, 2104-2110.

Warfvinge, C., Dahlblom, M., 2010. Projektering av VVS-installationer. Studentlitteratur, Lund, Sweden (in Swedish).

Xu, J., Wang, R.Z., Li, Y., 2014. A review of available technologies for seasonal thermal energy storage. Sol. Energy 103, 610-638.

Yumrutas, R., Unsal, M., 2012. Energy analysis and modeling of a solar assisted house heating system with a heat pump and an underground energy storage tank. Sol. Energy 86, 983-993. 